\title{
Does Big4 Audit Improve the Quality of Corporate Information, An Empirical Analysis Based on PSM
}

\author{
Hanxu Zhao \\ Business School, Hubei University, Wuhan 430062, Hubei Province, China
}

\begin{abstract}
Based on the PSM (Propensity Score Matching) approach, this paper presents a rigorous empirical argument to illustrate the statistical relationship between the audit background of the Big Four accounting firms and the quality of corporate accounting information, using a sample of all listed companies in Shanghai and Shenzhen A-shares from 2011 to 2020. This paper finds that after selecting the control and treatment groups under the PSM approach and solving the model endogeneity problem, the information quality of companies with the audit background of the Big Four accounting firms is significantly better than that of companies audited by ordinary accounting firms.
\end{abstract}

Keywords: PSM, Big4, Earnings management.

\section{Introduction}

"Integrity, ethics, adherence to standards, no false accounting" are the words proposed by Comrade Zhu Rongji for the China National Accounting Institute, which to a certain extent reflects the importance of the integrity of accountants. Similarly, for a listed company, "manipulating profits" can also be regarded as a kind of irresponsible and less than honest behaviour, which has led scholars to ponder what exactly triggers the manipulation of profits by listed companies, is it to directly whitewash the statements in order to obtain more investment financing? Or, what exactly are the factors that intervene to ensure the quality of accounting information of listed companies? Dr. Khaled AL Madhoun[1], in a recent study, pointed out that Fair Value Accounting (FVA) has a significant impact on the quality of accounting information. $\mathrm{Lu}$ [2] suggests that female sole directors with a financial background can improve the quality of corporate accounting information to some extent. Faouzi and Basma[3] have explored the impact of early adoption of IFRS on the quality of accounting information. This paper builds on previous research by further enriching the study of the factors affecting accounting information quality and using a more rigorous and appropriate PSM empirical approach to justify the findings.

\section{Data}

This paper has used all listed companies in Shanghai and Shenzhen A-shares from 2011 to 2020 as the sample, and used Stata 16.0 to screen and merge the sample data, and finally retained a total of 19,082 valid samples. Among the measures of accounting information quality, this paper selects Roychowdhury's (2006)[4] proposed to obtain the true surplus management REMi,t by calculating the abnormal cash flow from operating activities ABCFOi,t, abnormal production cost ABPRODi,t and abnormal discretionary expense ADBISEXPi,t respectively, which are calculated by the formulae as (1)-(4) are shown.

Since it is difficult to measure the quality of accounting information visually, the above approach allows the paper to calculate the amount of true surplus management (rem) corresponding to the sample companies as a proxy for the dependent variable in this paper, with the variable definition table shown in Table 1.

$$
\begin{gathered}
\mathrm{ABCFO}_{i, t}=\frac{C F O_{i, t}}{A_{i, t-1}}=\alpha_{0}+\alpha_{1}\left[\frac{1}{A_{i, t-1}}\right]+\alpha_{2}\left[\frac{S_{i, t}}{A_{i, t-1}}\right]+\alpha_{3}\left[\frac{\Delta S_{i, t}}{A_{i, t-1}}\right]+\varepsilon_{i, t} \\
A B P R O D_{i, t}=\frac{P R O D_{i, t}}{A_{i, t}}=\alpha_{0}+\alpha_{1}\left[\frac{1}{A_{i, t-1}}\right]+\alpha_{2}\left[\frac{S_{i, t}}{A_{i, t-1}}\right]+\alpha_{3}\left[\frac{\Delta S_{i, t}}{A_{i, t-1}}\right]+\alpha_{4}\left[\frac{\Delta S_{i, t-1}}{A_{i, t-1}}\right]+\varepsilon_{i, t} \\
A B D I S E X P_{i, t}=\frac{D I S E X P_{i, t}}{A_{i, t}}=\alpha_{0}+\alpha_{1}\left[\frac{1}{A_{i, t-1}}\right]+\alpha_{2}\left[\frac{S_{i, t-1}}{A_{i, t-1}}\right]+\varepsilon_{i, t} \\
\operatorname{REM}_{i, t}=-\frac{A B C F O_{i, t}}{A_{i, t-1}}+\frac{A B P R O D_{i, t}}{A_{i, t-1}}-\frac{A B D I S E X P_{i, t}}{A_{i, t-1}}
\end{gathered}
$$

Table 1: Definition of variables

\begin{tabular}{ccc}
\hline Type & Definition & Symbol/Content \\
\hline Dependent variable & Real Earnings Management & rem \\
Independent variable & Whether audited by a Big 4 accounting firm & growth, Operating income growth rate \\
& The company's ability to grow & size, Natural logarithm of total assets \\
& Size of the company & leval liabilities/total assets \\
Control variables & Leverage & at, Revenue from main business / Total Assets \\
& Total asset turnover ratio & roat Profit / Total Assets \\
& Return on total assets & Market Value/Book Value \\
\hline
\end{tabular}




\section{Empirical Analysis}

\subsection{Basic Analysis}

After completing the cleaning and integration of the raw data, the empirical analysis of the data can begin. Firstly, as the data samples in this paper are all continuous variables, except for the independent variable of whether or not they are audited by a Big 4 accounting firm, it is necessary to make appropriate treatment of outliers, as can be seen from Figures 1, 2 and 3 where the variables growth, roa and mb have more values that deviate from the whole.

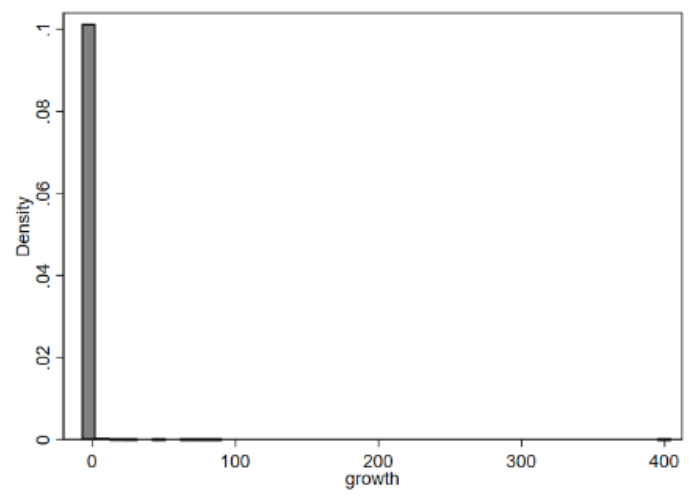

Figure 1: growth

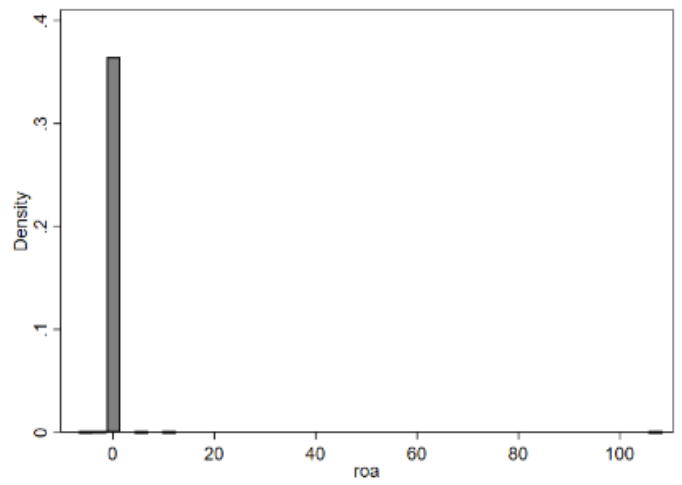

Figure 2: roa

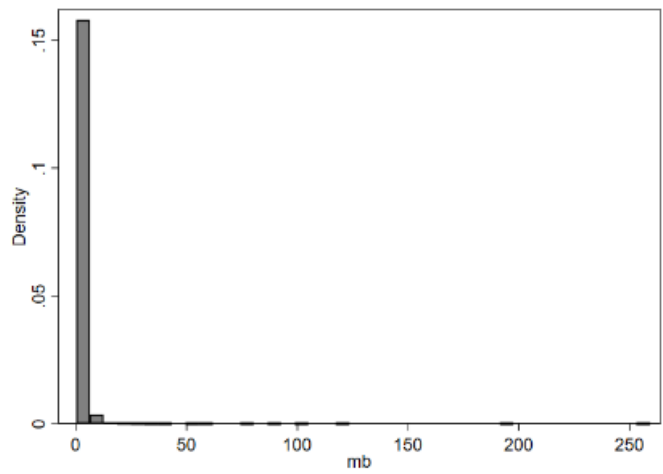

Figure 3: $\mathrm{mb}$

So it was necessary to shrink the tails of the three variables mentioned above, changing the outliers by $2.5 \%$ each before and after via wisnor2.

After completing the above tailing process, the initial descriptive statistics of the variables can be performed, and the results of the descriptive statistics of the variables are shown in Table 2.

Table 2: Descriptive statistics

\begin{tabular}{lllllll}
\hline & $\mathrm{N}$ & mean & $\mathrm{sd}$ & $\min$ & median & max \\
\hline rem & 19082 & -0.000 & 0.000 & -0.000 & -0.000 & 0.000 \\
big4 & 19082 & 0.059 & 0.236 & 0.000 & 0.000 & 1.000 \\
growth & 19082 & 0.069 & 0.165 & -0.256 & 0.043 & 0.639 \\
size & 19082 & 22.383 & 1.329 & 15.577 & 22.206 & 28.636 \\
lev & 19082 & 0.432 & 0.234 & -0.195 & 0.421 & 8.612 \\
at & 19082 & 0.000 & 0.000 & -0.000 & 0.000 & 0.000 \\
roa & 19082 & 0.031 & 0.054 & -0.153 & 0.029 & 0.148 \\
mb & 19082 & 2.054 & 1.226 & 0.905 & 1.641 & 6.440 \\
\hline
\end{tabular}

It is easy to see from the results of the descriptive statistics that the standard deviations of the variables are in a more reasonable range of values, which provides a valid prerequisite for the subsequent regression analysis. It can be seen that the values of real surplus management for the sample companies are very close to zero, showing values that are difficult to observe with the naked eye. The mean value of big4 shows that $5.9 \%$ of the companies in this sample were audited by the Big 4 . The rest of the variables are not repeated. The correlation coefficient table for the data is shown in Table 3.

Table 3: Correlation analysis

\begin{tabular}{|c|c|c|c|c|c|c|c|c|}
\hline & rem & big4 & growth & size & lev & at & roa & $\mathrm{mb}$ \\
\hline rem & 1.000 & & & & & & & \\
\hline big4 & -0.007 & 1.000 & & & & & & \\
\hline growth & $-0.070^{* * *}$ & -0.003 & 1.000 & & & & & \\
\hline size & $-0.027^{* * * *}$ & $0.357^{* * *}$ & $0.059^{* * *}$ & 1.000 & & & & \\
\hline lev & -0.008 & $0.091^{\text {**** }}$ & -0.007 & $0.396^{* * *}$ & 1.000 & & & \\
\hline at & $-0.176^{* * * *}$ & $-0.022^{* * * *}$ & $0.027^{\text {**** }}$ & $-0.144^{* * * *}$ & $-0.024^{* * * *}$ & 1.000 & & \\
\hline roa & $-0.025^{* * *}$ & $0.043^{* * *}$ & $0.275^{\text {*** }}$ & $0.020^{\text {*** }}$ & $-0.342^{* * *}$ & -0.002 & 1.000 & \\
\hline $\mathrm{mb}$ & $0.016^{* *}$ & $-0.100^{* * * *}$ & $0.020^{* * * *}$ & $-0.477^{* * * *}$ & $-0.234^{* * *}$ & $0.106^{* * * *}$ & $0.163^{* * * *}$ & 1.000 \\
\hline
\end{tabular}

By looking at the table of correlation coefficients for the variables, it is easy to see that there is a weak correlation between big4 and rem, but this may be due to the small number of companies audited by Big 4 firms as mentioned in the previous descriptive statistics, and it is worthwhile to do a $\mathrm{t}$-test to see if there is a statistical difference in rem between companies audited by Big 4 firms and those audited by non-Big 4 firms. The results of the t-test are shown in Figure 4.

\begin{tabular}{|c|c|c|c|c|c|c|}
\hline Group & Obs & Mean & Std. Err. & Std. Dev. & {$[95 \%$ Conf. } & Interval] \\
\hline$\theta$ & 17,957 & $4.46 e-14$ & $3.52 \mathrm{e}-12$ & $4.71 \mathrm{e}-10$ & $-6.85 e-12$ & $6.94 \mathrm{e}-12$ \\
\hline 1 & 1,125 & $-1.36 \mathrm{e}-11$ & $6.93 e-12$ & $2.32 \mathrm{e}-10$ & $-2.72 e-11$ & $-6.78 \mathrm{e}-15$ \\
\hline combined & 19,082 & $-7.60 e-13$ & $3.33 e-12$ & $4.61 \mathrm{e}-10$ & $-7.30 e-12$ & $5.78 e-12$ \\
\hline diff & & $1.37 e-11$ & $1.42 \mathrm{e}-11$ & & $-1.41 \mathrm{e}-11$ & $4.14 \mathrm{e}-11$ \\
\hline \multicolumn{4}{|c|}{ diff $=$ mean $(\theta)-$ mean $(1)$} & \multicolumn{2}{|c|}{$\mathrm{t}=$} & 0.9643 \\
\hline \multicolumn{3}{|c|}{ Ho: diff $=0$} & \multicolumn{3}{|c|}{ degrees of freedom } & 19080 \\
\hline \multicolumn{3}{|c|}{ Ha: diff $<0$} & \multicolumn{2}{|c|}{ Ha: diff $!=0$} & \multicolumn{2}{|c|}{$\begin{aligned} \text { Ha: } & \text { diff }>0 \\
\operatorname{Pr}(T>t) & =0.167\end{aligned}$} \\
\hline
\end{tabular}

Figure 4: Subgroup t-test 
From the above t-test results it is easy to see that Ha: diff!=0 corresponds to a p-value of 0.3349 , which indicates that the original hypothesis (H0: no difference between the two groups) cannot be rejected, and so the original hypothesis is chosen to be accepted that there is a statistical difference in the quality of accounting information (true surplus management) between companies audited by the Big 4 and those audited by non-Big 4 accounting firms.

\subsection{Regression Analysis}

After the above preliminary arguments, this paper finds that there is indeed a statistical difference between listed companies audited by Big 4 accounting firms and those audited by non-Big 4 accounting firms, and it is worthwhile to conduct further regression analysis to explore the reasons for this. The regression results are shown in Table 4 model (1), and it can be seen that the effect of big 4 on rem is not very significant, considering the previous descriptive Given the results of the previous descriptive and correlation analyses, it is doubtful that the number of companies audited by the Big 4 in China is too small, accounting for only $5.9 \%$ of the sample data, so it is highly likely that the endogeneity of the model is due to the inconsistent number of samples in the control and control groups. In order to solve this endogeneity problem, the PSM method was introduced to match the sample 1 to 1 . A total of 2,115 observations were obtained, and the values of the control variables in the control and treatment groups were all in the same range and close in number. After completing the PSM, the samples were regressed again and the regression results are shown in model (2) of Table 4.

Table 4: Regression results

\begin{tabular}{ccc}
\hline VARIABLES & $\begin{array}{c}\text { model }(1) \\
\text { rem }\end{array}$ & $\begin{array}{c}\text { model }(2) \\
\text { rem }\end{array}$ \\
\hline \multirow{2}{*}{ big4 } & 0.000 & $-0.000^{* * *}$ \\
growth & $(0.915)$ & $(-2.638)$ \\
& $-0.000 * * *$ & $-0.000 * * *$ \\
size & $(-8.141)$ & $(-5.689)$ \\
lev & $-0.000^{* * *}$ & $-0.000 * * *$ \\
& $(-4.920)$ & $(-4.018)$ \\
at & 0.000 & $0.000 * *$ \\
& $(0.804)$ & $(1.977)$ \\
roa & $-0.037 * * *$ & $-0.085 * * *$ \\
& $(-25.341)$ & $(-5.366)$ \\
mb & -0.000 & 0.000 \\
& $(-1.024)$ & $(0.417)$ \\
Constant & $0.000 * *$ & 0.000 \\
& $(2.184)$ & $(0.655)$ \\
& $0.000 * * *$ & $0.000 * * *$ \\
Observations & $(4.949)$ & $(4.119)$ \\
Number of stkcd & & 2,115 \\
\hline
\end{tabular}

Z-statistics in parentheses

$* * * \mathrm{p}<0.01, * * \mathrm{p}<0.05, * \mathrm{p}<0.1$

It is not difficult to find that the effect of big4 on rem becomes highly significant and negative at the $1 \%$ level of significance in the regression results after the PSM method. This indicates that the level of surplus management of listed companies with a Big 4 audit background is relatively significantly lower than that of listed companies without a Big 4 audit, which means that the quality of accounting information of companies audited by Big 4 firms is higher and more credible.

\section{Conclusions and Recommendations}

This paper uses the PSM (Propensity Score Matching) method to conduct an empirical analysis on a sample of all listed companies in Shanghai and Shenzhen A-shares from 2011 to 2020, and finds that audits by Big 4 accounting firms can effectively improve the quality of corporate accounting information, and that Big 4 audits also reduce the possibility of corporate surplus management. In response to the above findings, this paper proposes the following recommendations: when investing, investors can observe whether the accounting firm auditing the investee company is a Big Four firm in order to ensure the reliability of the quality of accounting information of the investee company in their non-professional capacity, so that they can reduce or avoid the adverse selection problem caused by information asymmetry when investing.

\section{References}

[1] Dr. Khaled AL Madhoun. The Relationship of Fair Value Accounting to the Quality of Accounting Information in Companies Financial Reports: View of the External Auditors in Palestine[J]. Journal of Economics, Finance and Accounting Studies, 2021, 3(1): 39-57.

[2] Yin Lu. Research on the Relationship between the Female Directors' Personal Characteristics and the Quality of Accounting Information[J]. SHS Web of Conferences, 2021, 96: 02008.

[3] Jilani F, Nfissa B B. The Impact of Early Adoption of IFRS on the Quality of Accounting Information[J]. International Journal of Accounting Research, 2019, 7(1): 1-8.

[4] Sugata Roychowdhury. Earnings Management through Real Activities Manipulation[J]. Journal of Accounting and Economics, 2006, 42(3): 335-370. 